\title{
MOOC at Universiti Sains Malaysia: factors impacting the teaching and learning outcomes of TITAS course
}

\begin{abstract}
A study has been conducted to investigate the factors that impacted the outcomes of teaching and learning of Tamadun Islam dan Tamadun Asia (TITAS) course among first year undergraduate students of Universiti Sains Malaysia (USM). This is part of a larger study that looks at the impact of Massive Open Online Course (MOOC) initiative of Ministry of Education Malaysia of four pilot courses offered during the first semester of 2014/2015 academic session. A total of 158 students enrolled in TITAS course responded to the 37 items-questionnaire. The respondents consist of male $(15.1 \%)$ and female $(84.8 \%)$ and majority of them $(86.7 \%)$ are competent in ICT. A factorial analysis was conducted to give patterns and structures to the data and provide a meaningful interpretation to the variables influencing the outcomes of the teaching and learning. The analysis revealed three components that explained a total of $56.80 \%$ of the variance. The first factor is the design of the learning activities (39.80\% of the variance) followed by the access to the learning materials (11.78\% of the variance) and the third factor can be attributed to curriculum compliance of learning course (5.21\% of the variance). The significant of the study is that it revealed of the importance of the design of learning activities for the successful implementation and delivery of MOOC. Equally important is the seamless access to the learning materials. Detailed discussion on these two factors will be put forward and as well as the appropriate interventions within the whole MOOC implementation framework.
\end{abstract}

Keyword: Massive open online course (MOOC); Enhancement in teaching and learning; Elearning; Learning activities; Learning materials 